\title{
Callogenesis and Organogensis Studies in Some Accessions of Saccharum officnarum L.
}

\author{
Smiullah ${ }^{1}$, Farooq Ahmad Khan ${ }^{1}$, Abdullah ${ }^{1}$, Rameez Iftikhar ${ }^{2}$, M Muzaffar Raza ${ }^{1}$, Rasheda Aslam ${ }^{1}$, \\ Ghazanfar Hammad ${ }^{1}$, Ambreen Ijaz ${ }^{3}$, Rana Haroon Maqsood ${ }^{1} \&$ Usman Ijaz $^{1}$ \\ ${ }^{1}$ Department of Plant Breeding and Genetics, University of Agriculture, Faisalabad, Pakistan \\ ${ }^{2}$ Agricultural, Food and Nutritional Science Department, University of Alberta, Edmonton, Canada \\ ${ }^{3}$ Department of Bioinformatics and Biotechnology, GC University, Faisalabad, Pakistan \\ Correspondence: Smiullah, Department of Plant Breeding and Genetics, University of Agriculture, Faisalabad, \\ Pakistan. E-mail: sami_1167pbg@yahoo.com
}

\author{
Received: December 27, 2012 Accepted: February 11, 2013 Online Published: March 15, 2013 \\ doi:10.5539/jas.v5n4p171 URL: http://dx.doi.org/10.5539/jas.v5n4p171
}

\begin{abstract}
The aim of the present study was to investigate the response of three sugarcane accessions viz., S-2003-US-824, S-2003-US-230 and SPF-246 for callogenesis and organogenesis. The genotypes showed high value of callus score ranging 2.37 to 2.7 . Genotype S-2003-US-824 was highest callus producer with an average of 2.7 callus score per test tube. Genotypes S2003-US-230 and SPF-246 were statistically similar with an average 2.37 and 2.49 respectively. Concentrations of 2, 4-D from $1-5 \mathrm{mg} / \mathrm{I}$ were considered to be the good for callus induction with best performance at $3 \mathrm{mg} / \mathrm{l}$. Leaf and pith explants showed good response to callus production but the leaf explant performed better with average callus score of 2.83 per test tube which is statistically different from pith explant (2.21). Thus, it can be inferred that leaf explant is a good source of callus induction than pith explant.
\end{abstract}

Keywords: explant, organogenesis, callus induction

\section{Introduction}

Sugarcane (Saccharum officinarum L.) is a major industrial cash crop and is widely cultivated in tropical and subtropical countries of the world for sugar and bioethanol production. It accounts for approximately $80 \%$ of the world's sugar production. Sugarcane is the second major cash crop in Pakistan and it is grown over one million hectares (Economic Survey of Pakistan, 2011). Despite of all efforts, sugarcane production in Pakistan is still much lower than most of the sugarcane growing countries of the world. The low cane and sugar yields are attributed to many factors in which drought; salinity, insect pests, and diseases are major constraints (Nasir et al., 2000; Khaliq et al., 2005). High ploidy, low fertility, large genome, complex environmental interactions, slow breeding advances, and backcrossing for the introduction of specific genes make conventional breeding difficult for this crop. In Pakistan, sugarcane flowers only in lower Sindh coastal areas, Jabban valley in Malakand agency, Khyber Pakhtoon Khawa and at Murrree hills, but viability is still a problem due to unfavorable climatic conditions. Thus, lack of viable fuzz production makes it difficult to improve sugarcane through conventional breeding in Pakistan. Micro propagation is currently the only realistic means of achieving rapid, large-scale production of disease-free quality planting material as seed canes of newly developed varieties in order to speed up the breeding and commercialization process in Sugarcane (Lorenzo et al., 2001). Because of which plant regeneration through tissue culture technique would be a viable alternative for improving the quality and productivity in sugarcane.

There are reports on tissue culture of sugarcane from different countries but the first attempts to regenerate plants through in vitro technique were made on sugarcane by Naz (2003) in Pakistan. Standardization of protocols for in vitro multiplication of sugarcane through callus culture, axillary bud and shoot tip culture have been reported by many authors. The present communication demonstrates an effective high frequency regeneration method, which allows for expedient multiplication of micro plants that are easily established ex vitro through callus culture of young meristem as an explant. The aim of the present study was to investigate the response of three sugarcane accessions viz., S-2003-US-824, S-2003-US-230, and SPF-246 for callogenesis and organogenesis. 


\section{Material and Methods}

The micropropagation studies were done as a collaborative research, between Department of Plant Breeding \& Genetics, University of Agriculture, Faisalabad and Agriculture Biotechnology Research Institute (ABRI), Ayub Agricultural Research Institute (AARI), Faisalabad. Healthy young meristems were collected by removing the leaf sheath from field grown plants of sugarcane accessions SPF-246, S-2003-US-824, and S-2003-US-230, maintained in the Sugarcane Research Institute AARI Faisalabad and brought to the laboratory. These young meristems were cut into thin smaller pieces of 1.0 to $1.5 \mathrm{~cm}$ length. The slices taken within the meristem region are referred to as pith explants and those further from the meristem comprising of leaf roll referred to as leaf explants. The explants were washed thoroughly and were treated with $70 \%$ alcohol for 30 second to one minute, by 2-3 washes with sterile distilled water. All the above operations were performed under aseptic conditions in a laminar airflow cabinet.

The young meristem cutting explants were inoculated on to sterilized semisolid basal MS medium (Murashige and Skoogs, 1962) supplemented with different concentrations and combinations of different plant growth regulators. For callus induction different concentrations of 2, 4-D were tried such as 0.5, 1.0, 2.0, 2.5 and 3.0 $\mathrm{mg} / \mathrm{l}$, with MS basal medium.

For regeneration, three media combinations were tried using 10 replications for each given under. RM1= M.S basal media $+1 \mathrm{mg} / 1$ Kinetin, RM2=M.S basal media $+\mathrm{Kn} 0.5 \mathrm{mg} / 1+0.5 \mathrm{mg} / 1 \mathrm{NAA}$, RM3 $=$ M.S basal media + $480 \mathrm{mg} / \mathrm{l} \mathrm{Casein}$ hydrolysate $+1 \mathrm{mg} / \mathrm{l} \mathrm{Kinetin.} \mathrm{Elongated} \mathrm{micro} \mathrm{shoots} \mathrm{measuring} \mathrm{about} 5-6 \mathrm{~cm}$ in length were excised from culture tube and transferred to half-strength (1/2 MS) MS medium supplemented with same concentrations of IBA, NAA and IAA $(0.5-3.0 \mathrm{mg} / \mathrm{l})$. The $\mathrm{pH}$ of the medium was adjusted to 5.8 before gelling with Agar and prior to autoclaving for $20 \mathrm{~min}$ at $120^{\circ} \mathrm{C}$ and at $15 \mathrm{lbs}$ psi pressure. Sugar was added at the concentration of $30 \mathrm{gm} / 1$. molten medium of $20 \mathrm{ml}$ was dispensed into the culture tube and plugged with nonabsorbent cotton wrapped in one layer of cheesecloth. All the cultures were incubated in a growth room with a $16 \mathrm{~h}$ photoperiod except callus culture (cool, white fluorescent light $30 \mathrm{umol} \mathrm{m} \mathrm{s}^{-1}$ ) and the temperature was maintained at $25 \pm 30^{\circ} \mathrm{C}$ with $70-80 \%$ relative humidity in the culture room. Each treatment consisted of 10 replicates and repeated thrice. For better callus induction just after autoclaving the culture tube containing semisolid sterilized media should positioned, such a manner as if the inside semisolid media in the culture tube should spread to maximum towards one side only. For callus induction experiment culture tubes were kept under 20,25 and $30^{\circ} \mathrm{C}$ in complete dark or light/dark condition with $16 / 8 \mathrm{hrs}$ light/dark photoperiod with $140 \mathrm{umol}$ m-2s-1 light from cool, white fluorescent lamps. Plantlets with well-developed roots were removed from the culture medium. Washed the roots gently under running tap water and were transferred to plastic trays for hardening which contain autoclaved garden soil, farmyard manure and sand (2:1:1). The harden plantlets in the plastic trays were covered with porous polyethylene sheets for maintaining high humidity and were kept under shade in a net house for further growth and development. All were irrigated with 1/8 MS basal salt solution devoid of sucrose and inositol every 4 days for two weeks. After 30 days, the plantlets were transplanted in to the soil in field condition.

\subsection{Statistical Analysis}

Experiments were set up in a Completely Randomized Design (CRD) and each experiment usually had 10 replicates and was repeated three times. 20 to 30 explants were used per treatment in each replication. Observations were recorded on the percentage of response of callus formation, percentage of response of shoots, number of shoots per callus, shoot length, percentage of response of roots, roots per shoot, and root length respectively. The treatment means were compared using Duncan's Multiple Range Test (DMRT) at 5\% probability level according to K. I. Gomez and A. A. Gomez (1984).

\section{Results and Discussion}

\subsection{Callogenesis}

\subsubsection{Callus Induction Frequency}

Callus formation is influenced by a number of factors some of which are discussed in the present study in the analysis of variance table (ANOVA Table 1). The influential differences among genotypes, auxin (2, 4-D) levels, explant source and genotype $\mathrm{x}$ explant source was elucidated by analysis of variance table (Table 1). However, the interaction of genotypes $\mathrm{x}$ auxin levels, auxin levels $\mathrm{x}$ explant and interaction of all three factors i.e. genotypes $\mathrm{x}$ auxin levels $\mathrm{x}$ explant was non-significant in the study. 
Table 1. Analysis of variance table for callus initiation frequency (CIF)

\begin{tabular}{lcrrc}
\hline \multicolumn{1}{c}{ Source } & D.F & \multicolumn{1}{c}{ S.S } & \multicolumn{1}{c}{ M.S } & \multicolumn{1}{c}{ F-VALUE } \\
\hline Genotypes (G) & 2 & 5.580 & 2.790 & $4.2511^{*}$ \\
2,4-D levels (D) & 4 & 27.547 & 6.887 & $10.4932^{* *}$ \\
G x D & 8 & 1.553 & 0.194 & $0.2959^{\text {ns }}$ \\
Explant (Exp.) & 1 & 29.453 & 29.453 & $44.8781^{* *}$ \\
G x Exp. & 2 & 6.847 & 3.423 & $5.2161^{* *}$ \\
D x Exp. & 4 & 3.547 & 0.887 & $1.3510^{\text {ns }}$ \\
G x D x Exp. & 8 & 1.153 & 0.144 & $0.2197^{\text {ns }}$ \\
Error & 270 & 177.200 & 0.656 & \\
Total & 299 & 252.880 & & \\
\hline
\end{tabular}

Coefficient of Variation: $32.15 \%, * *=$ Highly significant at $\mathrm{p}<0.01 ; *=$ Significant at $\mathrm{p}<0.05$; ns $=$ Non significant

\subsubsection{Effects of Genotypes on CIF (Callus Initiation Frequency)}

The response of genotypes for callus initiation frequency (callus score) were significant statistically. Significant differences $(\mathrm{p}<0.05)$ were observed among the genotypes using DMRT. The genotypes showed high value of callus score ranging 2.37 to 2.7. Genotype S-2003-US-824 was highest callus producer with an average of 2.7 callus score per test tube. Genotypes S2003-US-230 and SPF-246 were statistically similar with an average 2.37 and 2.49 respectively. The genotype S-2003-US-230 appeared to be least callus producer with the average of 2.37 .

These results revealed that callogenesis response is under the influence of genotype. Gandonou et al. (2005a) determined the response of three sugarcane varieties and found that callus induction ability is genotypes dependent. Similar results were also reported by Seema et al. (2011) and Raza et al. (2010).

Table 2. Means of callus scores on three genotypes

\begin{tabular}{cc}
\hline Genotypes & Callus Scores \\
\hline S-2003-US-824 & $2.7 \mathrm{a}$ \\
SPF-246 & $2.49 \mathrm{ab}$ \\
S2003-US-230 & $2.37 \mathrm{~b}$
\end{tabular}

Values followed by different letters differ significantly at $0.05 \%$ significant level.

\subsubsection{Effects of Auxin (2, 4-D) Levels on CIF (Callus Initiation Frequency)}

Satisfactory callus formation was noticed in all levels of 2, 4-D used in the study but the differences were significantly high. D3 medium having $3 \mathrm{mg} / 1$ of 2, 4-D with an average of 3.050 callus scores was the best callus producer. Callogenesis response seen at D2 and D1 media was not statistically different from each other. Also the same with media D4 and D5. However, there performance was different from D3 media. The callus score of five media levels are $2.233,2.583,3.050,2.517$, and 2.217 respectively. The lowest response was shown at D5 media $(1 \mathrm{mg} / \mathrm{l})$ with average callus score of 2.217 .

It can be deduced from the results that concentration of 2, 4-D from 1-5 mg/I was considered to be the good for callus induction with best performance at $3 \mathrm{mg} / 1$. These results were consistent with Mamun et al (2004) who studied invitro micropropagation of two sugarcane varieties and found that $3 \mathrm{mg} / \mathrm{I}$ of 2, 4-D produced maximum callus. Many scientists have used 2,4-D for callus formation and found effective like Athar et al. (2009) obtained $100 \%$ callus induction in $3.0 \mathrm{mg} / \mathrm{L}$ of 2,4-D. Badawy, O. M et al (2008), Pandey et al. (2011) and Gandonou et al. (2005b) also obtained embryogenic callus from leaf bases at 3mg/l 2,4-D. Jahangir et al. (2010) and Shahid et al. (2011) worked on callus inductions of sugarcane using different harmonal levels and found satisfactory 
results at $3.0 \mathrm{mg} / \mathrm{L}$ of 2,4-D. In contrast Eldessoky et al. (2011) used sugarcane GT54-9(C9) cultivar and obtained best results producing embryonic calli at $4 \mathrm{mg} / 1$ 2,4-D.

Table 3. Means of callus scores on five 2, 4-D levels

\begin{tabular}{cc}
\hline 2, 4-D Levels & Callus scores \\
\hline D3 & $3.050 \mathrm{a}$ \\
D2 & $2.583 \mathrm{~b}$ \\
D1 & $2.517 \mathrm{bc}$ \\
D4 & $2.233 \mathrm{c}$ \\
D5 & $2.217 \mathrm{c}$ \\
\hline
\end{tabular}

\subsubsection{Effects of Explant on CIF (Callus Initiation Frequency)}

Both the explants tried for callus production, which had highly significant effect on callus production and were different from each other as is shown by the table 4. Both the explants showed good response to callus production but the leaf explant performed better with average callus score of 2.83 per test tube that is statistically different from pith explant (2.21).

Thus, it can be inferred that leaf explant is a good source of callus induction than pith explant. Thus is primarily due to excretion of phenols, which turned the whole pith brown, hindering proliferation. These results coincide with work of Niaz and Quraishi (2002) that used leaf, lateral bud and pith as an explant and found leaf as the best explant source. Mamun et al. (2004) also used leaf explant for callus induction in two sugarcane varieties. Shahid et al. (2011) demonstrated leaf as explant with $3.0 \mathrm{mg} / \mathrm{L}$ 2,4-dichlorophenoxy acetic acid gave the best results, both for callus induction and proliferation. Mamun et al. (2004) also reported similar observations.

Table 4. Means of callus scores on two explant sources

\begin{tabular}{cc}
\hline Explant & Callus Scores \\
\hline LEAF & $2.833 \mathrm{a}$ \\
PITH & $2.207 \mathrm{~b}$ \\
\hline
\end{tabular}

\subsubsection{Effects of (g x exp) on CIF (Callus Initiation Frequency)}

The genotypic response of sugarcane showed that genotypes performed well on both leaf and pith explant sources, but leaf explant source was better than pith explant statistically. Using leaf explant, maximum callus was produced by S2003-US-824 with an average callus score of 3.2 per test tube. However, genotypes S2003-US-230 and SPF-246 were statistically same with an average of callus score 2.5 and 2.8 per test tube with leaf explant. These results are opposed to the findings of Niaz and Quraishi (2002) who reported that pith explant showed better performance than leaf explant. All other interactions between Genotype x 2,4D level, 2, 4-D level $\mathrm{x}$ Explant source and Genotype $\mathrm{x}$ 2, 4-D level $\mathrm{x}$ Explant source were found non-significant for callogenesis in this study as per table 1.

\subsection{Organogenesis Studies}

Callus organogenesis or regeneration is also dependent on a number of factors. Regeneration response from callus was studied under the effects of three factors i.e., genotype, regeneration media, explants, and their interactions also have been observed for regeneration response. 
Table 5. Analysis of variance table for regeneration percentage (\%)

\begin{tabular}{lrrrc}
\hline Sov. & DF & \multicolumn{1}{c}{ SS } & \multicolumn{1}{c}{ MS } & \multicolumn{1}{c}{ F-VALUE } \\
\hline Genotype (G) & 2 & 1690.000 & 845.000 & $20.8992^{* *}$ \\
RM level (RM) & 2 & 4643.333 & 2321.667 & $57.4214^{* *}$ \\
G x RM & 4 & 66.667 & 16.667 & 0.4122 \\
Explant (Exp.) & 1 & 5780.000 & 5780.000 & $142.9557^{* *}$ \\
G x Exp. & 2 & 70.000 & 35.000 & 0.8656 \\
RM x Exp. & 2 & 370.000 & 185.000 & $4.5756^{*}$ \\
G x RM x Exp. & 4 & 100.000 & 25.000 & 0.6183 \\
Error & 162 & 6550.000 & 40.432 & \\
Total & 179 & 19270.000 & & \\
\hline
\end{tabular}

$* *=$ Highly significant at $\mathrm{p}<0.01 ; *=$ Significant at $\mathrm{p}<0.05 ; \mathrm{ns}=$ Non significant

The analysis of variance table for percentage regeneration response showed that there were significant differences among genotypes, regeneration media, explant sources, and interaction of regeneration media $\mathrm{x}$ explant sources. While the interactions between genotype $x$ regeneration media $(G \times R M)$, genotype $x$ explant sources ( $\mathrm{G} \times$ Exp) and genotype $\mathrm{x}$ regeneration media $\mathrm{x}$ explant sources ( $\mathrm{G} \times \mathrm{RM} \times \mathrm{Exp})$ were non-significant.

\subsubsection{Genotypic Response for Regeneration}

The analysis of variance depicted that there was significant difference in the response of genotypes to the organogenesis in sugarcane. S-2003-US-824 proved to be the most responsive to organogenesis with an average percent of 43\%. Genotypes, SPF-246 and S2003-US-230 were statistically different in regeneration behavior from S-2003-US-824 with an average percent of 39.5 and 35.5 respectively. Based on S-2003-US-824 performance; it can be concluded that this genotype was observed to be more callus producer and more in regeneration response showing that callogenesis and organogenesis are dependent on each other. Therefore, we can say that successful regeneration is under the control of genotypic behavior. The similar results are reported by Rahman et al. (2002) who also observed different genotypic behavior towards organogenesis. Gill et al. (2004) studied that factors affecting, somatic embryogenesis and subsequent plant regeneration in vitro sugarcane cultures were highly genotype specific. Significant differences were observed among sugarcane genotypes in their regeneration ability indicating that in vitro regeneration is a genotypic dependent trait (Gandonou et al., 2005a). Similar results were also reported by Raza et al. (2010) in sugarcane. Khan et al. (2009) observed non-significant difference in shoot induction from three different sugarcane cultivars.

Table 6. Means of regeneration percentages on genotypes

\begin{tabular}{cc}
\hline Genotypes & Regeneration \% age \\
\hline S-2003-US-824 & $43.00 \mathrm{a}$ \\
SPF-246 & $39.50 \mathrm{~b}$ \\
S2003-US-230 & $35.50 \mathrm{c}$ \\
\hline
\end{tabular}

\subsubsection{The Effect of Regeneration Media on Organogenesis}

As the analysis of variance table 5 showed that the regeneration media, RM 1 (M. S. basal media $+1 \mathrm{mg} / 1$ Kinetin), RM2 (M. S. basal media $+0.5 \mathrm{mg} / 1$ kinetin $+0.5 \mathrm{mg} / 1$ Naphthalene acetic acid) and RM3 (M. S. basal media supplemented with $480 \mathrm{mg} / 1$ casein hydrolysate $+0.5 \mathrm{mg} / \mathrm{l}$ kinetin) were statistically different in response of regeneration. The following Duncan Multiple Range test table showed significant difference between three regeneration media and the RM2 showed better regeneration response with average percent of $46.17 \%$ as compared to RM1 and RM3 with average percent of 37.83 and 34 respectively, On the basis of above results, it can be concluded that high level of cytokinin and low level of Auxin is essential for regeneration of shoots in sugarcane leaf sheath callus. It was also observed that type and concentration of growth regulators used in culture medium had significant effect on shoot induction. Earlier reports showed that combination of NAA with 
Kinetin promoted rapid regeneration from sugarcane callus. Niaz and Quraishi, (2002) also determined that media containing Kinetin, addition of NAA significantly increased the number of shoot production. However, no shoots were observed on media containing Kinetin $(2.0 \mathrm{mg} / \mathrm{l})$ with and without NAA, which confirmed that high concentration of growth hormones might, hinder the regeneration ability. Eldessoky et al. (2011) used sugarcane GT54-9 (C9) cultivar and observed vigorous shoot regeneration when NAA was used with BAP. Similarly Khan et al. (2009) studied three sugarcane clonal lines and observed best results on medium containing $1.5 \mathrm{mg} / \mathrm{l} \mathrm{Kin} \mathrm{+}$ $1 \mathrm{mg} / \mathrm{l} \mathrm{NAA}$.

Table 7. Comparison of Regeneration media level means for regeneration percentage

\begin{tabular}{cc}
\hline Regeneration media levels & Regeneration percentage \\
\hline Level 2 & $46.17 \mathrm{a}$ \\
Level 1 & $37.83 \mathrm{~b}$ \\
Level 3 & $34.00 \mathrm{c}$ \\
\hline
\end{tabular}

\subsubsection{The Influence of Explant on Regeneration}

The analysis of variance showed that explant source had significant role in the regeneration response from the callus produced. The leaf proved to be the best explant for regeneration of plantlets from callus with an average percent of 45 than pith with an average percent of 33.667. These results were according to the expectations. The leaf being soft in nature produced soft, granular, and embryogenic callus in nature thus showed more regeneration response while hard callus of pith produced from mature part showed less number of plantlets. These results were consistent with the findings of Rahman et al. (2002). It was also found that regeneration was dependent upon the concentration of growth hormones and type of explants used (Shahid et al. 2011). All the interactions between genotype $\mathrm{x}$ RM level, genotype $\mathrm{x}$ explant source, RM level x explant source and genotype $\mathrm{x}$ RM level x explant source were found to be not significant.

Table 8. Comparison of Explants source means for regeneration percentage

\begin{tabular}{cc}
\hline Explants' source & Regeneration percentage \\
\hline Leaf & $45 \mathrm{a}$ \\
Pith & $33.667 \mathrm{~b}$ \\
\hline
\end{tabular}

\subsubsection{Interactional Response of Regeneration Media and Explants}

The regeneration media interact differently with the explant sources. Regeneration medium RM2 showed maximum regeneration response at leaf explant with an average percent of 53.67. The poorest response was of RM3 at the pith explant with an average percent of 30. So regeneration medium (RM2) and leaf explant were concluded as the better for plant regeneration in sugarcane. Research in future may elucidate some more precise medium and explant for regeneration.

The regenerated plants when attained the height of 4 to 5 inches were shifted to half strength M.S. rooting media. When they established roots were transferred to pots for hardening and later shifted to field.

\section{Conclusions}

All verities used in the study were new so protocol was established by checking their responses to different hormonal levels. The study made on hormones level and explants of varieties of the sugarcanes shows that the explants regeneration on culture in vitro depends to a great part on the genetic potentialities of these varieties. Based on S-2003-US-824 performance; it can be concluded that this genotype was observed to be more callus producer and more in regeneration response showing that callogenesis and organogenesis are dependent on each other. Study also revealed that in sugarcane by using leaf as an explant gives better results than pith. The proposed study was also helpful to produce virus free plants of sugarcane for sugarcane mosaic virus disease. At the end, work will be quite useful for the rejuvenilization of sugarcane varieties banned in country due to disease attack. 


\section{References}

Anonymous. (2011). Pakistan Economic Survey, Finance Division, Government of Pakistan, Retrieved from www. finance.gov.pk

Ather, A., Khan, S., Rehman, A., \& Nazir, M. (2009). Optimization of the protocols for callus induction, regeneration and acclimatization of sugarcane cv. thatta-10. Pakistan Journal of Botany, 41(2), 815-820.

Badawy, O. M., Nasr, M., I., \& Alhendawi, R. A., (2008). Response of sugarcane (Saccharum species hybrid) genotypes to embryogenic callus induction and in vitro salt stress. Sugar Tech, 10(3), 243-247. http://dx.doi.org/10.1007/s12355-008-0043-8

Eldessoky, D. S., Ismail, R. M., Hadi, A., Hadi, A., \& Abdallah, N. (2011). Establishment of regeneration and transformation system of sugarcane cultivar GT54-9 (C9). GM Crops, 2-2, 126-134.

Gandonou, C., Abrini, J., Idaomar, M., \& Senhaji, N. S. (2005a). Response of sugarcane (Saccharum sp.) varieties to embryogenic callus induction and invitro salt stress. Mr. J. Biotech., 4(4), 350-354.

Gandonou, C., Errabii, T., Abrini, J., Idaomar, M., \& Senhaji, N. S. (2005b). Effect of genotype on callus induction and plant regeneration from leaf explant of sugarcane (Saccharum sp.). Afr. J. Biotech., 4(11), $1250-1255$.

Gill, N. X., Raman, G., Gosal, S. S., \& Gill, R. (2004). Somatic embryogenesis and plant regeneration in some commercial cultivarsof sugarcane. Crop Improv., 29, 28-34.

Gomez, K. I., \& Gomez, A. A. (1984). Statistical procedure for agricultural research. New York, USA: Jhon Willey and Sons.

Jahangir, G. Z., Nasir, I. A., Sial, R. A., \& Javed, M. A. (2010). Various hormonal supplemented activate sugarcane regeneration in vitro. $J$ Agri Sci, 2, 231-237.

Khaliq, A., Ashfaq, M., Akram, W., Choi, J. K., \& Lee, J. (2005). Effect of plant factors, sugar contents, and control methods on the Top Borer (Scirpophaga nivella F.) Infestation in selected varieties of sugarcane. Entomological Res., 35, 153-160. http://dx.doi.org/10.1111/j.1748-5967.2005.tb00152.x

Khan, I. A., Dahot, M. U., Seema, N., Yasmeen, S., Bibi, S., \& Naqvi, M. H. (2009). Direct regeneration of sugarcane plantlets: A tool to unravel genetic Heterogenety. Pak. J. Bot., 41(2), 797-814.

Lorenzo, J. C., Ojeda, E., Espinosa, A., \& Borroto, C. (2001). Field performance of temporary immersion bioreactor derived sugarcane plant vs. In vitro cell Dev. Biol., Plant, 37, 803-806. http://dx.doi.org/10.1007/s11627-001-0133-8

Mamun, M. A., Sikdar, M. B. H., Paul, D. K., Rahman, M. M., \& Islam, M. R. (2004). In vitro micropropagation of some important sugarcane varieties of Bangladesh. Asian J. Pl. Sci., 3(6), 666-669. http://dx.doi.org/10.3923/ajps.2004.666.669

Murashige, T., \& Skoog, F. (1962). A revised medium for rapid growth and bioassays with tobacco tissue cultures. Physiol. Plant., 15, 473-497. http://dx.doi.org/10.1111/j.1399-3054.1962.tb08052.x

Nasir, N. M., Qureshi, R. H., \& Aslam, M. (2000). Effect of salinity on emergence of sugarcane lines. Pak. Sugar J., 15, 12-14.

Naz, S. (2003). Micropropagation of promising varieties of sugarcane and their acclimatization response. Activities on Sugar Crops in Pakistan. Proc. Fourth Workshop Res. \& Dev., 1-9.

Niaz, F., \& Quraishi, A. (2002). Studies on Somatic Embryogenesis in Sugarcane. J. Biol. Scie. 2(2), 67-69. http://dx.doi.org/10.3923/jbs.2002.67.69

Pandey, R. N., Rastogi, J., Sharma, M. L., \& Singh, R. K. (2011). Technologies for cost reduction in sugarcane Micropropagation. Afr. J. Biotech., 10(40), 7814-7819.

Rahman, S. U., Shahid, M. T. H., Hussain, M., Tanvir, M. K., \& Javed, M.A. (2002). Genotypic effect on callogenesis and organogenesis in sugarcane. Pak. Sugar J., 17(6), 13-20. http://dx.doi.org/10.4238/vol10-3gmr1122

Raza, G., Ali, K., Mukhtar, Z., Mansoor, S., Arshad, M., \& Asad, S. (2010). The response of sugarcane (Saccharum officinarum L) genotypes to callus induction, regeneration and different concentrations of the selective agent (geneticin -418). Afr. J. Biotech., 9(51), 8739-8747. 
Seema, N, Oad, F. C., Khan, I. A., Tunio, S., Siddiqui, M. A., Yasmin, S., ... Bibi, S. (2011). Influence of phytohormone on the organogenesis of sugarcane. Pak. J. Bot., 43(3), 1531-1534.

Shahid, M. T. H., Khan, F. A., Saeed, A., \& Fareed, I. (2011). Variability of red rot-resistant somaclones of sugarcane genotype S97US297 assessed by RAPD and SSR. Genet. Mol. Res., 10(3), 1831-1849. 